\title{
Avaliação de um Centro de Atenção Psicossocial: o olhar da família
}

\author{
Evaluation of a Psychosocial Care Center: the view of the family
}

Marcio Wagner Camatta ${ }^{1}$

Cíntia Nasi ${ }^{1}$

Angélica Nickel Adamoli ${ }^{2}$

Luciane Prado Kantorski ${ }^{3}$

Jacó Fernando Schneider ${ }^{4}$
${ }^{1}$ Universidade Federal de Ciências da Saúde de Porto Alegre (UFCSPA). Rua Sarmento Leite 245, Centro. 90050-170 Porto Alegre RS.mcamatta@gmail.com ${ }^{2}$ Educadora física da Prefeitura Municipal de Porto Alegre

${ }^{3}$ Faculdade de Enfermagem e Obstetrícia da Universidade Federal de Pelotas (UFPel)

${ }^{4}$ Escola do Programa de Pós-Graduação em Enfermagem da Universidade Federal do Rio Grande do Sul (UFRGS)

\begin{abstract}
This study sought to evaluate a Psychosocial Care Center from the perspective of the users' family members. Qualitative research was carried out, based on the theoretical and methodological references of Fourth Generation Evaluation. Gathering of data was made in a mental health unit in Porto Alegre, Rio Grande do Sul State, Brazil, between October and November 2006, when 13 family members of users were interviewed. At a later stage, the interviews were validated in a negotiation workshop. Data were grouped and discussed, according to the topics: environment, therapeutic activities, team, plasticity, inclusion of the family, results of psychosocial attention, public policies and society. The data negotiation workshop was an important moment of discussion and reflection about the themes that emerged from the interviews. This evaluation shows the importance of giving voice to family members and view them as partners for establishing mental healthcare that fits in with the principles and guidelines of the Unified Health System and the tenets of Brazilian psychiatric reform.

Key words Mental health, Mental health services, Family, Evaluation
\end{abstract}

Resumo O objetivo deste estudo foi avaliar um Centro de Atenção Psicossocial na perspectiva de familiares de usuários do serviço. Foi realizada uma pesquisa qualitativa utilizando-se do referencial teórico-metodológico da Avaliação de Quarta Geração. A coleta ocorreu em um serviço de saúde mental de Porto Alegre em outubro e novembro de 2006, por meio de entrevistas com 13 familiares, posteriormente validadas em uma oficina de negociação. Os dados foram agrupados e discutidos segundo as temáticas: ambiência, atividades terapêuticas, equipe, plasticidade, inserção da família, resultados da atenção psicossocial, políticas públicas e sociedade. A oficina de negociação dos dados foi um momento importante de discussão e reflexão sobre as temáticas que emergiram das entrevistas. Essa avaliação demonstra a importância em dar voz e em considerar os familiares como parceiros para a produção de uma atenção em saúde mental que coadune com os princípios e diretrizes do Sistema Único de Saúde e com os pressupostos da reforma psiquiátrica brasileira. Palavras-Chave Saúde mental, Serviços de saúde mental, Família, Avaliação 


\section{Introdução}

O campo da saúde mental brasileira vem desde o final do século XX, sofrendo importantes transformações nas políticas, na organização dos serviços e nas práticas de saúde. Esse período tem se mostrado profícuo para a constituição de um novo paradigma para a atenção em saúde mental, pautado nos direitos humanos e na defesa e exercício da cidadania - o paradigma da Atenção Psicossocial.

A Atenção Psicossocial tem sustentado um conjunto de ações teórico-práticas, político-ideológicas e éticas norteadas pela aspiração de substituir o Modo Asilar pelo Modo Psicossocial'1. O primeiro tem por objeto a doença mental, o hospital psiquiátrico como meio e a cura como finalidade, já o segundo tem por objeto a existência-sofrimento, diversos dispositivos sociais como meios e por finalidade a reabilitação psicossocial e reinserção social do sujeito em sofrimento psíquico.

Os pressupostos do modo psicossocial foram incorporados pelo movimento da reforma psiquiátrica brasileiro, o qual teve uma importante influência do movimento da Psiquiatria Democrática Italiana. Os princípios da reforma têm se materializado no contexto brasileiro por meio de decretos do Ministério da Saúde e também pela criação de novos serviços ${ }^{2}$.

Quanto aos aspectos teórico-práticos do campo da atenção em saúde mental vale ressaltar a produção de novos dispositivos e formas de intervenção, dentre os quais se destaca os Centros de Atenção Psicossocial (CAPS). Esses equipamentos de saúde têm sido adotados pelo Ministério da Saúde como os articuladores da rede de atenção em saúde mental, com o intuito de prestar cuidado aos sujeitos em sofrimento psíquico e sua família em um dado território, vislumbrando a substituição dos hospitais psiquiátricos.

Tendo em vista o trabalho dos profissionais do CAPS estar voltado para a dimensão individual e social dos sujeitos em sofrimento psíquico, a família e a comunidade têm sido incluídas na construção de práticas pautadas no modo psicossocial.

O trabalho da equipe do CAPS, por possuir uma proposta terapêutica alicerçada neste modo de atenção, tem contribuído para a diminuição de crises dos sujeitos e de internações psiquiátricas. No entanto, as ações da equipe têm-se voltado eminentemente para o usuário, ficando a família à margem desta atenção ${ }^{3}$.

O trabalho no modo psicossocial só pode ser concretizado mediante a parceira e a participa- ção familiar, pois, embora se espere que o CAPS atenda as necessidades das famílias no que tange aos aspectos relacionados diretamente ao enfrentamento do sofrimento psíquico, a equipe deve considerar ainda a participação e inserção da família mediante sua acolhida, integração e cuidado nos espaços cotidianos da vida, tais como no trabalho, lazer e moradia ${ }^{4}$.

Mais do que uma aliada na efetivação do modo psicossocial, a família deve ser foco de intervenção dos profissionais do CAPS, para que seus anseios sejam acolhidos e sua sobrecarga minimizada, pois, frequentemente, a família que tem entre seus membros um em sofrimento psíquico apresenta sobrecargas de diferentes tipos, sejam elas financeira, física, emocional ou referentes ao cuidado ${ }^{5}$.

Não se trata apenas de acolher o sofrimento, mas de desenvolver outras estratégias que também contribuam para a adesão da família ao serviço, tais como a criação de vínculo, a participação em grupos de autoajuda, a mediação de conflitos, a negociação e a implicação dos profissionais com os problemas psíquicos e sociais do usuário e da família ${ }^{6}$.

Considerando a importância do envolvimento da família no cuidado aos sujeitos em sofrimento psíquico e da necessidade de suporte e apoio das equipes para os familiares desses sujeitos, torna-se relevante avaliar a compreensão que a família possui sobre o CAPS.

Diante da possibilidade de imprimir uma forma de avaliação em que se leve em conta as opiniões de atores diretamente interessados no funcionamento dos serviços de saúde mental optou-se pelo referencial teórico-metodológico da Avaliação de Quarta Geração ${ }^{7}$. Trata-se de uma avaliação que, mediante um processo participativo, pode ser um dispositivo para os familiares ampliarem as possibilidades de intervenção na realidade do serviço, uma vez que frequentemente estão excluídos em metodologias tradicionais8.

Destaca-se nesse referencial o caráter formativo, na medida em que propicia aos sujeitos partilharem decisões, exercerem controle sobre o projeto de avaliação, se apropriarem dos diferentes passos da avaliação e terem honradas suas participações no processo avaliativo. Dessa maneira, busca-se a qualificação das informações e o empoderamento dos sujeitos envolvidos?.

O objetivo desta pesquisa foi avaliar um Centro de Atenção Psicossocial na perspectiva de familiares de usuários. Esta pesquisa torna-se relevante por dar voz aos familiares de usuários de um CAPS, propiciando que reflitam e discutam 
sobre as práticas de saúde, a organização do CAPS e as políticas de saúde mental. Reconhece-se que este estudo se desenvolveu em uma grande cidade com mais de um milhão de habitantes, contudo os resultados encontrados e discutidos nesta pesquisa podem contribuir para que outras equipes de CAPS, em regiões com características semelhantes ao cenário aqui descrito, possam refletir sobre suas práticas, transformando-as, ou mesmo atribuindo-lhes novos sentidos.

\section{Metodologia}

Este estudo está vinculado ao projeto de pesquisa "Avaliação dos Centros de Atenção Psicossocial da Região Sul do Brasil” (CAPSUL), financiado pelo edital do Ministério de Ciência e Tecnologia do Conselho Nacional de Pesquisa/ Ministério da Saúde. Nesse projeto, de abordagem quanti-qualitativa, foram definidos como sujeitos de pesquisa - equipes dos CAPS, usuários e familiares.

No processo teórico-metodológico desta pesquisa, foi utilizada a Avaliação de Quarta Geração proposta por Guba e Lincoln ${ }^{7}$ e adaptado por Wetzel ${ }^{8}$. Este referencial tem caráter formativo, pois visa a fornecer informações para adequar e superar aspectos problemáticos do serviço durante o processo avaliativo, bem como um caráter responsivo por considerar as reivindicações, preocupações e questões dos sujeitos para repensar a organização do serviço ${ }^{7}$.

Essa avaliação é implementada por meio dos pressupostos metodológicos do paradigma construtivista, sendo que os parâmetros e limites da avaliação são determinados mediante um processo interativo e de negociação que envolve os sujeitos da pesquisa ${ }^{7}$.

Nesse artigo destaca-se a etapa qualitativa do CAPSUL realizada em um CAPS II, no município de Porto Alegre, tendo como sujeitos do estudo os familiares de usuários atendidos no CAPS. A coleta de dados ocorreu de outubro a novembro de 2006, com 13 familiares de usuários do CAPS em estudo, sendo utilizado como critérios de inclusão tanto os familiares inseridos no serviço, como aqueles que não participavam da dinâmica do mesmo.

Como instrumento de coleta de dados foi utilizado entrevistas com os familiares, as quais foram gravadas e transcritas na íntegra. As questões iniciais das entrevistas foram: - fale sobre o atendimento no serviço; - fale sobre os fatores que possam contribuir para o melhor funciona- mento do serviço; - fale sobre a gestão da política municipal de saúde mental.

Para a operacionalização da avaliação foi utilizado o círculo hermenêutico dialético, o qual é hermenêutico devido ao seu caráter interpretativo e dialético por implicar comparação e contraste de diferentes pontos de vista objetivando um espaço de interlocução dos sujeitos e, quando possível, alcançar um consenso ${ }^{8}$.

No início do Círculo, foi realizada uma entrevista, em que foi solicitado ao primeiro entrevistado que discorresse sobre as questões. Após cada entrevista foi realizada uma análise prévia dos depoimentos para identificar aspectos da avaliação para apreciação do próximo entrevistado, além das questões inicias propostas para o primeiro. Desta maneira, a partir do segundo entrevistado, todos os outros eram convidados a responder as três questões inicias e a opinar a respeito das construções que foram surgindo ao longo das análises das entrevistas de cada sujeito do estudo.

A partir da análise prévia dos dados coletados foram construídos núcleos temáticos, os quais foram apresentados aos sujeitos da pesquisa para negociação. Esta etapa consiste na devolução dos dados preliminares da avaliação e permite que os sujeitos discutam sobre os temas levantados, oportunizando a eles modificar ou afirmar a credibilidade desses temas. A negociação, enquanto uma estratégia do processo da Avaliação de Quarta Geração foi realizada mediante a utilização de técnica grupal, contando com a participação de todos os entrevistados.

$\mathrm{Na}$ análise dos dados, as questões surgidas a partir da análise prévia das entrevistas e da negociação, foram agregadas em núcleos temáticos previamente definidos - marcadores internos e externos.

A pesquisa respeitou os aspectos éticos previstos pelo Conselho Nacional de Saúde e foi garantido o sigilo e anonimato dos sujeitos da pesquisa por meio da utilização do Termo de Consentimento Livre e Esclarecido e pela identificação dos depoimentos pela letra "F" (familiares). O projeto de pesquisa foi aprovado pelo Comitê de ética em Pesquisa da Faculdade de Medicina da Universidade Federal de Pelotas.

\section{Resultados e Discussões}

A análise dos depoimentos que emergiram do processo avaliativo do CAPS foi realizada tendo por base temas previamente definidos e organi- 
zados conforme as dimensões internas e externas ao serviço, denominados como Marcadores Internos e Externos. Os Internos compreendem ambiência, características da equipe, atividades terapêuticas, plasticidade e inserção da família; os Externos incluem políticas públicas e a relação da sociedade com a loucura.

\section{Marcadores Internos}

Os familiares ao abordarem aspectos relacionados à estrutura do serviço relatam satisfação com o espaço físico, mas também, destacam a necessidade de melhorias na estrutura, conforme os depoimentos que seguem: Acho que não foi construido especificamente para ser um local de abrigar pessoas com problemas ou fazer oficinas, vários salões, mas está bem dividido, supre todas as necessidades. Tem refeitório, tem os consultórios, tem a área de lazer. (F8). Acho que poderia ser pintado, ter uns bancos melhores, umas portas melhores, ter uma janela melhor, poderia não morrer de calor aqui dentro no verão, muitas coisas poderiam ser melhoradas porque nem um ventilador tem, então acho isso muito ruim. (F7).

A ambiência foi um dos fatores estudados no serviço, sobretudo quanto ao espaço físico, um dos aspectos deste conceito que visa, entre outras finalidades, ao conforto, à privacidade e à individualidade dos sujeitos envolvidos, valorizando o ambiente, garantindo conforto aos usuários e trabalhadores enquanto um espaço que possibilita o encontro de subjetividades ${ }^{10}$.

Embora os familiares relatem sobre a adequação de alguns espaços físicos no CAPS, fica evidente que este serviço possui uma série de inadequações estruturais que interferem, em alguma medida, na produção de saúde, sejam devido à percepção de um ambiente físico não acolhedor, seja no desconforto gerado pelo mobiliário existente e pela falta de equipamentos.

Por meio da confortabilidade, a ambiência tem componentes que atuam como modificadores e qualificadores do espaço, buscando a criação de ambientes acolhedores e na impressão de uma percepção ambiental mais harmônica e agradável, tendo em vista a sua contribuição significativa no processo de produção de saúde ${ }^{11}$.

Quanto às características do trabalho da equipe, os familiares destacaram a qualificação técnica dos profissionais que realizam o atendimento no CAPS, bem como o seu envolvimento na atenção ao usuário, como ilustra a seguinte fala: $O$ atendimento é muito bom, eu diria excelente, por que você encontra tudo aquilo que tu espera. Bons profissionais, pessoas interessadas, pessoas preocupadas com o paciente, todos muito treinados. (F1).

Trabalhar em saúde mental requer aprofundamento no conhecimento específico desta área, pois ela possui algumas características peculiares ao sofrimento psíquico do usuário. Assim, o profissional do CAPS busca na qualificação de sua formação subsídios para lidar neste campo de conhecimento, tendo em vista a melhoria no atendimento e a construção de conhecimento, contribuindo para a consolidação de um serviço de saúde mental mais efetivo ${ }^{12}$.

As características da equipe do CAPS são percebidas pela família mediante o reconhecimento da qualificação profissional e do envolvimento e responsabilização na atenção em saúde mental ao usuário. Nesse depoimento o interesse e a implicação da equipe com o usuário configuramse como uma característica marcante no trabalho dessa equipe.

A implicação desses profissionais com os usuários necessariamente perpassa uma dimensão relacional, em que os sujeitos sociais estão envolvidos em uma relação de proximidade, escuta, reflexão, comprometimento e respeito. Essas características remetem ao entendimento de que as interações humanas constituem-se como uma importante estratégia que deve ser explorada no espaço de implementação de cuidado no âmbito da saúde mental.

Nesse sentido, o trabalho do CAPS deve estar alicerçado na reflexão e no questionamento sobre os saberes e as práticas, e, sobretudo, na experimentação de relações interpessoais mais dialógicas e na escuta do outro, conduzindo para uma "clínica do encontro", pois aí reside a força e a delicadeza desse trabalho em saúde ${ }^{13}$.

Os familiares apontaram como atividades terapêuticas do CAPS as oficinas terapêuticas, as visitas domiciliares e o atendimento a pessoas em situação de rua. Eles reconhecem a importância das oficinas terapêuticas no atendimento do seu familiar em sofrimento psíquico no CAPS, tanto para maior inserção no espaço do serviço, como para a ajuda específica no tratamento. A fala do familiar, a seguir, relatando a participação de um usuário nestas atividades, enriquece esta questão: [...] ele faz poesia, tem oficina da escrita, tem a oficina culinária, oficina do vídeo, oficinas de futebol e a oficina da saúde. Isso ajuda bastante ele, no caso se adaptar ao local e as pessoas que estão em tratamento também, ajudam ele até nessas coisas de insônia, de pesadelo, de tirar essas angústias, essas tristezas. (F10).

As oficinas são importantes estratégias terapêuticas, que podem possibilitar a inserção ou 
reinserção social dos sujeitos no mundo da coletividade, onde os mesmos poderão romper com o isolamento e reinventar a vida em seus aspectos cotidianos ${ }^{14}$. As oficinas são espaços terapêuticos e de convivência, com um fazer atrelado a este espaço, que busca viabilizar e potencializar possibilidades de expressão para o usuário.

A diversidade dessa modalidade de trabalho, ofertada pela equipe do CAPS, tem levado a resultados identificados pelos familiares como a promoção do convívio social entre os próprios usuários e destes com os profissionais do serviço, além de ajudar no enfrentamento do sofrimento do usuário.

Alguns familiares ao abordarem sobre as visitas domiciliares consideram-nas como um importante recurso terapêutico. Entretanto, com as seguintes falas percebe-se que alguns familiares não receberam esse tipo de atendimento, além de outros que não tinham conhecimento dessa atividade no serviço: Eu nunca tive visita domiciliar, mas acho que é bom. Tu vê se realmente tem condições do aspecto da própria pessoa que está doente se tem condições de melhorar. (F10). A minha mãe não recebeu nenhuma visita ainda. Nem sabia que tinha. (F12).

Com essas falas pode-se observar que embora as visitas domiciliares sejam um recurso fundamental no atendimento em serviços substitutivos, para melhor acompanhamento dos usuários e de seus familiares, talvez essa atividade esteja sendo pouco utilizada pela equipe do CAPS. A partir de tal situação, pode-se presumir que esta atividade não tem sido realizada com frequência pela equipe devido à precariedade de recursos ou talvez pela não priorização dessa atividade pela equipe.

Outra atividade realizada pelo CAPS, considerada relevante para os familiares, é o atendimento às pessoas em situação de rua, destacada na seguinte fala: Acho que não há preconceito. Eles ajudam tanto quem tem moradia, quanto o que mora na rua. Acho que o atendimento é igual para todos, não tem diferença nenhuma. (F13).

Os familiares não vêem diferença na maneira de atendimento dos usuários do CAPS que possuem moradia daqueles que estão em situação de rua, remetendo para ideia de que o tratamento é igual para todos. Esta ideia nos remete para a diretriz da equidade do Sistema Único de Saúde, a qual frequentemente adquire um sentido restrito à simples oferta de tratamento igualitário para todos, incorrendo ao entendimento enquanto sinônimo da diretriz de igualdade.

Contudo, a equidade não possui um sentido restrito à mera oferta de tratamento igualitário para todos, mas abarca também a orientação para que os serviços e profissionais de saúde ofereçam o respeito traduzido em práticas e atitudes destinadas a cada cidadão em suas necessidades ${ }^{15}$. Essas necessidades são específicas a cada indivíduo e/ou grupo populacional, sendo necessário, portanto, a adequação das ações de saúde voltadas para as necessidades peculiares das pessoas e/ou grupos distintos.

Assim, a equidade significa "o respeito às subjetividades e ao direito à saúde de cada pessoa, cada segmento da população brasileira, segundo as suas particularidades e singularidades". Desta maneira, as necessidades das pessoas e grupos surgem a partir de suas diferenças, e os serviços devem criar condições para que estas necessidades específicas sejam atendidas ${ }^{15}$.

A plasticidade é entendida enquanto a capacidade que o serviço tem ou não de acolher as diversas demandas para além das questões relacionadas à doença, estendendo-se para a vida do usuário. Sobre esta questão, os familiares destacaram que o serviço disponibiliza um quadro variado de atividades que potencializam suas capacidades, além de proporcionar a oportunidade de qualificação profissional ao usuário através de cursos, como expresso nos depoimentos a seguir: Meu guri teve um curso, ele não está trabalhando por que ele não tem anos, mas ajudaram muito, nessa atitude, diploma [...] É ele fez de porteiro, assessor e serigrafia, fez um monte de curso. (F2). Eles fazem coisa de dança, eles já tentaram muito, porque ela faz crochê, eles já tentaram conseguir para ela participar de feiras, para vender as coisas, estão sempre procurando uma coisa [...] ela passou várias tardes lá no CAPS sendo orientada em trabalhos, em atividades que ela podia fazer com idosos [...] eu acho que eles procuram dar além de saúde mental da pessoa, uma coisa para que eles se sintam úteis. (F4).

Esses depoimentos ilustram a perspectiva que os familiares possuem sobre a plasticidade do CAPS na medida em que o trabalho da equipe busca a reabilitação psicossocial dos usuários, procurando irromper com práticas restritas ao cuidado fisiopatológico, expandindo assim para um cuidado que vise à reinserção social de fato, ampliando o poder de contratualidade dos usuários no cotidiano de suas vidas - mediante uma profissão ou uma atividade laboral.

Essa plasticidade não deve recair somente sobre a dimensão laboral, mas quando se faz necessário, os profissionais procuram agenciar moradia, lazer, alimentação, escola, etc., pois tais dimensões da vida dos usuários ganham visibili- 
dade e sentido para os profissionais de saúde mental quando se ocupam desses temas para a produção de saúde das pessoas ${ }^{6}$.

Sobre a inserção da família no CAPS, um entrevistado evidencia que há pouca participação da família no serviço, o que interfere e prejudica no tratamento do usuário. Além disso, esse entrevistado destaca a necessidade de maior atenção à família, oportunizando momentos de escuta a esses. No entanto, outro familiar ressalta em sua fala, a disponibilidade dos profissionais para atender a família. Que eles dessem mais atenção ao familiar, porque o familiar sofre junto, sofre muito mais que o paciente. Tem que ter a hora do familiar poder falar. (F5). Os médicos e os demais profissionais estão à disposição dos familiares. (F9).

Ao mesmo tempo em que um familiar relata a necessidade de ser escutado pelos profissionais, outro diz que estes estão disponíveis para esta interação. Apesar dessa divergência quanto à atenção a família dos usuários, tem-se como essencial que os profissionais devem estar abertos ao encontro e ao diálogo contínuo com os familiares, com o intuito de estabelecer uma relação de compreensão mútua e de compartilhamento de responsabilidades na atenção em saúde mental.

Envolver a família no tratamento, de forma a ampará-la, apoiá-la e orientá-la na difícil tarefa de ser cuidadora do usuário deve fazer parte do trabalho de um serviço de saúde mental como o CAPS, tendo em vista que frequentemente a família é desassistida em seu cotidiano ${ }^{16}$. Conhecer e compreender a história de vida das da família, e dos familiares dos usuários, pode servir como uma potente estratégia da equipe do CAPS na atenção em saúde mental, pois, estar junto às famílias pode potencializar o enfrentamento das adversidades impostas às mesmas em seu cotidiano, possibilitando a elas conduzir suas vidas de maneira mais agradável e menos sofrida ${ }^{17}$. Por estar junto, entende-se o estabelecimento de uma postura dialógica entre os profissionais e a família, pois, desta maneira, ampliam-se as possibilidades de uma efetiva parceria entre esses sujeitos sociais.

Segundo os familiares, os resultados da atenção psicossocial, promovida pelo CAPS, são identificados sob a forma dos usuários apresentarem um melhor convívio familiar e social, bem como, a estabilização do quadro psíquico configurada pela redução de crises, como nos relatam os depoimentos a seguir: antes ele estava só no quarto, chegava visita lá em casa e ele não queria nem saber quem era. Hoje ele está uma pessoa bem mais sociável, conversa com as pessoas normal- mente, sem aquela vergonha que tinha; vai ao banco resolve as coisas dele. (F1). Antes ela tinha muitas recaídas, agora ela conseguiu manter. (F12).

$\mathrm{O}$ atendimento no CAPS possui, entre outras, a finalidade de minimizar as dificuldades no convívio social e a de ampliar as possibilidades do usuário em conduzir sua própria vida, tendo por horizonte a inserção social e a promoção de autonomia do usuário.

O estigma que os sujeitos em sofrimento psíquico são submetidos na sociedade acaba por impor barreiras para que tenham autonomia na condução de suas vidas. Assim, destaca-se como fundamental para promover a inclusão social de pessoas em sofrimento psíquico a garantia de que possam exercer os seus direitos à autonomia pela liberdade de fazerem suas próprias escolhas ${ }^{18}$.

\section{Marcadores Externos}

Quanto às políticas públicas os familiares em seus depoimentos revelam diferentes aspectos, como a distribuição de medicações psicotrópicas, a necessidade de ampliação do número de profissionais do serviço e a importância do aumento do número de CAPS.

Quanto à política de medicação do município um familiar relata não possuir conhecimento sobre quem é o responsável por ela e acrescenta que gostaria que o CAPS voltasse a oferecer remédios que antes eram distribuídos no próprio serviço, como fica evidenciado na seguinte fala: Antes, a farmácia dava os remédios para os pacientes, não precisava a pessoa estar correndo, $e$ tiraram daqui. [...] Às vezes tem lá num bairro, mas não pode tirar (a medicação) por que não é daquele setor, está péssima a parte da secretaria (saúde). Eu não sei quem é que comanda, é nosso prefeito é? (F2).

Identifica-se, com essa fala, que os familiares não se sentem contentes com a mudança que houve na distribuição dos medicamentos psicotrópicos, que anteriormente eram disponibilizados diretamente no CAPS, facilitando a captação dos mesmos, e que agora devem ser buscados em unidades de saúde, os quais nem sempre são de fácil acesso aos usuários e familiares. Além disso, os familiares não compreendem a lógica da gestão e das políticas de saúde mental do município, temáticas relevantes para a efetiva participação dos familiares nesse contexto. Entende-se, que o seu envolvimento na discussão das políticas de saúde mental pode propiciar uma consciência crítica e o exercício de sua cidadania, conduzindo-o a uma postura de protagonista, 
junto aos usuários e profissionais do CAPS, para a construção de uma atenção em saúde mental digna.

Destaca-se a importância de maior entendimento acerca da gestão pública por usuários e familiares do CAPS, já que políticas públicas dizem respeito a todos, sendo, portanto de todos, sendo necessário resgatar esse sentido de coletividade, provocando um agir coletivo no exercício da ação cotidiana com o envolvimento dos diversos agentes que estão nele implicados ${ }^{19}$. A família é uma parceira imprescindível ao trabalho dos profissionais de saúde mental, destacando-se como um elemento importante para a consolidação de políticas públicas em saúde mental ${ }^{17}$, juntamente com os profissionais e os usuários ${ }^{20}$.

Ainda com relação às políticas públicas, os familiares destacam em seus depoimentos a necessidade de mais profissionais e a ampliação de CAPS na cidade, bem como a divulgação do mesmo: Precisaria aumentar, ter mais profissionais para atender um número maior de pessoas. A estrutura é boa, mas acho que precisa aumentar, as pessoas precisam e a psiquiatria está muito cara para quem não pode. [...] ter mais CAPS nos bairros. (F1). Eu vejo isso como uma falha, talvez até do gestor. Muitos profissionais da saúde não sabem que existe (CAPS); muitas pessoas não sabem o que é um CAPS. (F7).

Com esses depoimentos fica evidenciado que os familiares consideram importante tanto que o CAPS atenda um maior número de usuários, como da necessidade de um maior número de CAPS no município. Tal necessidade constatada pelos familiares decorre da compreensão de que a psiquiatria privada possui elevados valores, sendo pouco acessível para a população em geral. Também, pode-se supor que tal necessidade do aumento do número de CAPS, ocorre pela valorização que os familiares atribuem a esse serviço no atendimento ao seu familiar.

Além disso, os familiares sinalizam para a pouca divulgação de serviços substitutivos como os CAPS na comunidade, identificando essa falta de divulgação do serviço como uma falha na gestão municipal. Diante de tal constatação remetese a necessidade de maior divulgação dos serviços substitutivos junto à sociedade, tanto para tentar facilitar o acesso da população aos CAPS, como para desmistificar o imaginário social de que a saúde mental é alvo somente de atendimento nos moldes dos hospitais psiquiátricos e da psiquiatria privada.

Nesse sentido, a falta de interesse político dos gestores e a insuficiência da aplicação de recursos por parte dos poderes públicos envolvidos com a saúde mental levam a dificuldades no que concerne a consolidação da reforma psiquiátrica, interferindo diretamente nos serviços substitutivos, como os CAPS ${ }^{21}$. Além do mais, a gestão das políticas de saúde mental municipal reflete diretamente no cotidiano do trabalho da equipe de saúde mental junto aos usuários e seus familiares. Estes sentem as interferências, sobretudo na insuficiência do número de serviços de administração pública no município e no sucateamento dos serviços existentes ${ }^{17}$.

Sobre a relação da sociedade com a loucura os familiares dos usuários do CAPS tecem algumas considerações sobre a pouca divulgação dos CAPS na sociedade e a necessidade desse serviço estar inserido no cotidiano da comunidade, como exemplificado no seguinte depoimento: Eu sabia que tinha postos de tratamento, mas não sabia como funcionava e, realmente, eu não tinha nenhuma ideia. Eu acho que falta mais divulgação. E da maneira como divulgar, porque aqui em Porto Alegre, parece que está em todo Brasil, a mudança de postos, no caso tirar o paciente de hospitais para colocar em postos [...] nos outros grupos que a minha mãe participava, que eles tinham de artesanato onde eles também vendiam, tinham exposições, iam para feiras para vender. Então eu acho que teria, deveria ter alguma coisa assim mais fora do posto, aqui do CAPS, para eles terem um contato maior. (F12).

Os familiares apontam para a necessidade dos CAPS serem mais divulgados junto à sociedade para que possam ter maior visibilidade e inserção na vida comunitária. Além disso, eles reconhecem que essa modalidade de serviço substitutivo é uma inovação presente em todo país, que visa desinstitucionalizar os sujeitos que anteriormente eram mantidos em instituições hospitalares.

A política de saúde mental, em consonância com os princípios da reforma psiquiátrica brasileira, tem centrado suas ações no município por acreditar que é ali que as transformações na assistência em saúde mental são possíveis, já que esse é o cenário em que as pessoas vivenciam o seu cotidiano ${ }^{20}$. Dessa maneira, os familiares têm observado uma mudança na lógica de atenção em saúde mental, ao comparar os novos serviços de saúde mental em contraposição aos hospitais psiquiátricos tradicionais, demonstrando uma necessidade de maior esclarecimento à sociedade sobre essa mudança.

Os familiares destacam ainda que deveriam ser implementadas ações que proporcionassem maior participação do CAPS junto à comunida- 
de, como atividades de feiras de artesanato. Esse movimento de aproximação e inclusão do CAPS na comunidade é de fundamental importância para proporcionar aos usuários a reinserção social, por meio de atividades desportivas, de artesanato, de cultura, de lazer, dentre outras.

Assim, destaca-se que não basta desconstruir e criar novos espaços de atenção em saúde mental, mas, sobretudo, deve-se inventar novas formas de lidar, conviver e tratar a loucura nos diferentes espaços sociais, como nos bairros, nas ruas, nas escolas, nas famílias, entre outros ${ }^{20}$.

Com a ampliação de serviços substitutivos em saúde mental, como os CAPS, pode ser possibilitada maior inserção da pessoa em sofrimento psíquico na comunidade, ajudando a modificar a concepção que a sociedade tem da loucura. Além dessa ampliação dos serviços substitutivos, deve-se considerar que as equipes desses serviços devem estar constantemente se perguntando sobre os saberes e práticas empregados em seu cotidiano, a fim de evitar a reprodução de uma lógica manicomial no CAPS.

\section{Negociação}

A oficina de negociação dos dados coletados foi realizada a partir de uma análise prévia do material obtido das entrevistas, em que fora, apresentados os dados aos entrevistados, de forma que esses pudessem ter acesso à totalidade de informações e ter a oportunidade de modificálas ou afirmar sua credibilidade ${ }^{11}$.

Os resultados que surgiram a partir do círculo hermenêutico-dialético foram organizados em núcleos temáticos mediante uma análise prévia das entrevistas dos familiares. Assim, seguem os principais eixos que foram discutidos durante a oficina de negociação.

A discussão sobre o atendimento à população em situação de rua desenvolvido no CAPS foi polêmica, pois, alguns familiares pensam que esta população deveria ser internada, no entanto, uma familiar se manifestou contra, argumentando que a internação não é a melhor forma de tratamento. Segundo esta familiar, todos deveriam ter o mesmo tratamento, pois, as pessoas em situação de rua também precisam de cuidado.

A partir dos próprios depoimentos dos familiares, foi discutida a necessidade dos médicos serem mais atenciosos no lidar com a família do usuário. Quanto a esta discussão, uma familiar argumentou que sempre foi atendida em suas demandas pelo profissional, contrapondo tal afirmação perante o grupo.
Outra discussão que gerou polêmica no grupo, foi a afirmação quanto a garantia de acesso à medicação. Houve unanimidade entre os presentes quanto à falta de organização na distribuição dos medicamentos psicotrópicos e a falta de garantia de acesso aos mesmos.

Outro aspecto relevante que os familiares questionaram foi a necessidade de divulgação dos serviços que funcionam nos mesmos moldes que o CAPS.

Destaca-se que o momento da negociação serviu de espaço de encontro, discussão, confraternização, de resgate de memórias de situações e acontecimentos vivenciados pelos familiares. Nem sempre o grupo dos familiares chegou a um consenso quanto às temáticas, mas considera-se como fundamental o espaço propiciado de discussões e reflexões entre esses atores.

\section{Considerações finais}

A utilização do referencial teórico-metodológico da Avaliação de Quarta Geração mostrou-se como um relevante referencial de pesquisa na condução de estudos avaliativos no campo da saúde mental, pois permitiu uma maior compreensão de algumas dimensões das políticas de saúde mental, da organização dos serviços e das práticas profissionais na perspectiva de familiares de usuários de um CAPS.

Sob a ótica dos familiares, os CAPS têm se mostrado como um importante dispositivo de saúde mental, os quais contam com a atuação de profissionais qualificados e oferecem uma diversidade de estratégias de cuidado, tais como oficinas terapêuticas, visitas domiciliares e o atendimento de pessoas em situação de rua, visando à reabilitação psicossocial e a reinserção social dos usuários. Contudo, considerando a visita domiciliar como uma importante estratégia de cuidado em saúde mental fica o questionamento sobre a aparente subutilização deste recurso pela equipe, o que mereceria maior investigação.

Vale ressaltar o reconhecimento que os familiares atribuem ao empenho da equipe em considerar o atendimento aos sujeitos em situação de rua, demonstrando o esforço desta equipe e deste serviço em agregar as diferenças, como as de um determinado grupo populacional marginalizado, bem como considerar as necessidades particulares de cada sujeito atendido. Assim, a equipe tem procurado se moldar às diversas demandas que surgem, atuando numa perspectiva de cuidado para além da doença, estendendo-se 
para a vida do usuário, com o intuito de proporcionar-lhes a ampliação de seu poder de contratualidade social.

Outra característica marcante desta equipe, de acordo com os familiares, diz respeito ao tipo de relação que esses profissionais adotam nos encontros com os usuários e familiares. Essas relações têm se caracterizado pela adoção de uma postura atenta, de proximidade e respeito, de escuta e comprometimento, o que tem contribuído para resultados positivos na atenção em saúde mental, demonstrando assim a relevância na qualidade dos encontros e das interações entre os sujeitos sociais.

O estabelecimento de parceria com os familiares e a sua integração ao tratamento do usuário foram destacados como ações que devem ser continuamente problematizadas pela equipe, tendo em vista que o diálogo e a compreensão recíproca podem contribuir para o compartilhamento de responsabilidades na atenção em saúde mental entre os envolvidos nesta relação.

Os depoimentos dos familiares demonstram ainda a necessidade de um maior envolvimento deles na discussão das políticas de saúde mental a fim de subsidiá-los na adoção de uma postura de protagonista, junto aos usuários e profissionais de saúde mental, para a consolidação dos pressupostos da reforma psiquiátrica brasileira.

Por fim, vale destacar a importância dada à divulgação dos CAPS como equipamento de saúde mental público, bem como a ampliação do número de profissionais e deste tipo de serviço no município. Somadas a esses investimentos, os familiares ressaltaram a necessidade do serviço estudado em se inserir mais na vida cotidiana da comunidade. Essas ações contribuiriam para a diminuição do imaginário social sobre o louco e a loucura, além de potencializar a reinserção social dos usuários.

Observa-se que neste estudo a relevância de se construir juntos aos familiares uma avaliação em que esses sujeitos sociais possam opinar e discordar de temas que julgam pertinentes aos CAPS quanto às práticas de saúde, à organização do serviço e às políticas de saúde mental. Essa avaliação demonstra a importância em dar voz e em considerar esses sujeitos como parceiros para a produção de uma atenção em saúde mental que coadune com os princípios e diretrizes do Sistema Único de Saúde e com os pressupostos da reforma psiquiátrica.

\section{Colaboradores}

MW Camatta, C Nasi, AN Adamoli, LP Kantorski e JF Schneider participaram igualmente de todas as etapas da elaboração do artigo. 


\section{Referências}

1. Costa-Rosa A, Luzio CA, Yasui S. Atenção psicossocial: rumo a um novo paradigma na saúde mental coletiva. In: Amarante P, organizador. Archivos de saúde mental e atenção psicossocial. Rio de Janeiro: NAU; 2003. p. 13-44.

2. Kantorski LP. Mental Health Care in Brazil. J Psychiatr Ment Health Nurs 2002; 9(3):251-253.

3. Camatta MW, Schneider JF. O trabalho da equipe de um Centro de Atenção Psicossocial na perspectiva da família. Rev. Esc. Enferm. USP 2009; 43(2):393400 .

4. Schrank G, Olschowsky A. O Centro de Atenção Psicossocial e as estratégias para a inserção da família. Rev. Esc. Enferm. USP 2008; 42(1):127-134.

5. Borba LO, Schwartz E, Kantorski LP. A sobrecarga da família que convive com a realidade do transtorno mental. Acta paul. enferm. 2008; 21(4):588-594.

6. Silva MBB. Reforma, responsabilidades e redes: sobre o cuidado em saúde mental. Cien Saude Colet 2009; 14(1):149-158.

7. Guba E, Lincoln Y. Fourth Generation Evaluation. Newbury Park: Sage; 1989.

8. Wetzel C. Avaliação de serviço em saúde mental: a construção de um processo participativo [tese]. Ribeirão Preto: Escola de Enfermagem de Ribeirão Preto, Universidade de São Paulo; 2005.

9. Kantorski LP, Wetzel C, Olschowsky A, Jardim VMR, Bielemann VLM, Schneider JF. Avaliação de quarta geração - contribuições metodológicas para a avaliação de serviços de saúde mental. Interface - Comunic, Saúde, Educ 2009; 13(31):343-355.

10. Brasil. Ministério da Saúde. Secretaria de Atenção à Saúde. Núcleo Técnico da Política Nacional de Humanização. Ambiência. 2a ed. Brasília: Editora do Ministério da Saúde; 2007. 32 p. (Série B. Textos Básicos de Saúde).

11. Kantorski LP, coordenador. CAPSUL - Avaliação dos CAPS da Região Sul do Brasil: Relatório. Pelotas: Conselho Nacional de Desenvolvimento Científico e Tecnológico (CNPq), Ministério da Saúde (MS); 2008.

12. Schneider JF, Camatta MW, Nasi C. O trabalho em um Centro de Atenção Psicossocial: uma análise em Alfred Schutz. Rev gauch. enferm. 2007; 28(4):520526.
13. Nunes M, Torrente M, Ottoni V, Moraes Neto V, Santana M. A dinâmica do cuidado em saúde mental: signos, significados e práticas de profissionais em um Centro de Assistência Psicossocial em Salvador, Bahia, Brasil. Cad Saude Publica 2008; 24(1):188-196.

14. Rauter C. Oficinas para que? uma proposta éticoestético-política para oficinas terapêuticas. In: Amarante P, organizador. Ensaios: subjetividade, saúde mental, sociedade. Rio de Janeiro: Fiocruz; 2006.

15. Costa AM, Lionço T. Democracia e gestão participativa: uma estratégia para a equidade em saúde? Saude soc. 2006; 15(2):47-55.

16. Waidman MAP, Gusmão R. Família e cronicidade da doença mental: dúvidas, curiosidade e relacionamento familiar. Fam. saude desenvolv. 2001; 3(2): 154-162.

17. Camatta MW. Vivências de familiares sobre o trabatho de uma equipe de saúde mental na perspectiva da sociologia fenomenológica de Alfred Schutz [dissertação]. Porto Alegre: Escola de Enfermagem, Universidade Federal do Rio Grande do Sul; 2008.

18. Korr WS, Encandela JA, Brieland D. Independence or autonomy: which is the goal? Int J Law Psychiatry 2005; 28(3):290-299.

19. Cabral BEB. Reflexões sobre a prática em saúde mental: o desafio de manter a tensão. In: Rosa EM, Novo HA, Barros MEB, Moreira MIB, organizadores. Psicologia e saúde: desafios as políticas públicas no Brasil. Vitória: EDUFES; 2007.

20. Vianna PCM, Barros S. O papel das políticas sociais frente à reestruturação do modelo assistencial em saúde mental. Saude em debate 2005; 29(69):27-35.

21. Oliveira WF, Dorneles P. Patrimônio e ambiente da loucura: a formação do profissional de saúde mental e o diálogo com a vida da cidade. In: Amarante P, organizador. Archivos de Saúde Mental e Atenção Psicossocial 2. Rio de Janeiro (RJ): Nau; 2005. p.13-43.

Artigo apresentado em 30/08/2009

Aprovado em 18/01/2010

Versão final apresentada em 04/02/2010 